\title{
SOROEPIDEMIOLOGIA DA TOXOPLASMOSE EM GATOS E CÃES DE PROPRIEDADES RURAIS DO MUNICÍPIO DE JAGUAPITÃ, ESTADO DO PARANÁ, BRASIL ${ }^{1}$
}

\section{SEROEPIDEMIOLOGY OF TOXOPLASMOSIS IN CATS AND DOGS FROM RURAL PROPERTIES OF JAGUAPITÃ COUNTY, PARANÁ STATE, BRAZIL}

\author{
João Luis Garcia ${ }^{2}$ Italmar Teodorico Navarro ${ }^{3}$ Liza Ogawa $^{4}$ Rosângela Claret de Oliveira $^{4}$
}

RESUMO

O presente estudo determinou a soroprevalência da toxoplasmose em gatos e cães localizados na zona rural do município de Jaguapitã, Estado do Paraná, através da reação de imunofluorescência indireta para detecção de anticorpos antiToxoplasma gondii da classe IgG, considerando-se reagentes títulos maiores ou iguais a 1:16. Observou-se uma prevalência de $73 \%$ em 163 soros felinos e $84,1 \%$ em 189 soros caninos, sendo que nas duas espécies não houve diferença em relação ao sexo. Em relação aos felinos, o título mais freqüente foi 1: 4096 $(28,6 \%)$ e o maior título encontrado foi de 1:65536 (0,8\%), apresentando diferenças estatísticas com relação ás faixas etárias, e com aumento da soropositividade com a idade. Os títulos mais freqüentes nos caninos foram 1:64 (38,4\%), e o maior título foi de 1:4096 (1,9\%), com soropositividade menor nos animais com menos de 8 meses. Não houve correlação significativa na distribuição dos títulos de anticorpos entre felinos e caninos. Através do presente trabalho, verificou-se que o $\mathrm{T}$. gondii está amplamente distribuído na população felina e canina da região.

Palavras-chave: toxoplasmose, soroprevalência, cães, gatos, Toxoplasma gondii.

\section{SUMMARY}

The present study was designed to stablish the seroprevalence of toxoplasmosis in cats and dogs from a rural area of the Jaguapitã county, Paraná state, Antibodies againstToxoplasma gondii were detected by indirect immunofluorescence test. Titers than 1:16 were considered positive. A prevalence rate of $73 \%$ and $84.1 \%$ was observed for cats and dogs respectively. There was no difference related to sender. The most frequent titer in cats was 1:4096 (28.6\%), whereas the highest titer found was 1:65536 (0.8\%). There was a statistical significant increase in seropositivity with age. The most common titers in dogs was 1:64 (38.4\%), whereas the highest titer was 1:4096 (1.9\%). There was a decrease in seropositivity in dogs with less than 8 of age. There was no significant correlation in the distribuition of titers between dogs and cats. Based on our data we conclude that $\boldsymbol{T}$. gondii is widely distributed in dogs and cats from this region.

Key words: toxoplasmosis, seroprevalence, dog, cat, Toxoplasma gondii.

\section{INTRODUÇÃO}

O Toxoplasma gondii está amplamente distribuído no mundo (DUBEY, 1993) e segundo BANETH et al. (1996), podem infectar todos os animais de sangue quente. DUBEY et al. (1995b) o consideram uma protozoonose de grande interesse, seja para os homens ou para os animais, devido às sérias conseqüências da infecção.

Felídeos são os únicos que eliminam oocistos pelas fezes (MILLER $\boldsymbol{e t}$ al., 1972); esses sofrem esporulação no meio ambiente, e tornam-se infectantes em 1 a 5 dias (DUBEY, 1993). O papel dos felinos é de suma importância na transmissão da doença (DUBEY et al., 1995a) e o risco da infecção está associado ao número de gatos infectados, pois o meio ambiente torna-se mais contaminado (WEIGEL $\boldsymbol{e t} \boldsymbol{a l} .$, 1995). A infecção congênita em

${ }^{1}$ Estudo financiado pela CPG-UEL/CAPES/CNPq.

${ }^{2}$ Médico Veterinário, Prefeitura Municipal de Jaguapitã, PR, Brasil. Mestrando de Sanidade Animal, Universidade Estadual de Londrina, (UEL), Londrina, PR, Brasil.

${ }^{3}$ Professor do Departamento de Medicina Veterinária Preventiva. UEL, Caixa Postal 6001, 86050-970 Londrina, PR, Brasil. E-mail: italmar@npd.uel.br. Autor para correspondência.

${ }^{4}$ Acadêmicas do Curso de Medicina Veterinária, bolsistas do CNPq. 
felinos é rara, e dentre os sinais clínicos principais estão: anorexia, letargia e pneumonia, sendo este último o mais importante que pode apresentar-se com ou sem tosse (DUBEY \& BEATTIE, 1988).

Duas formas da doença são observadas em cães, uma severa multisistêmica e normalmente fatal, mais comum em cães jovens, a outra localizada no sistema nervoso central e periférico (DUBEY et $\boldsymbol{a l} ., 1990$ apud BANETH $\boldsymbol{e} \boldsymbol{t} \boldsymbol{a l} ., 1996)$. JACKSON et al.(1987) relataram que uma prevalência elevada da toxoplasmose em cães, pode demonstrar um ambiente altamente contaminado, visto que a infecção é facilitada pelos seus hábitos alimentares e estreito contato com o solo (DURAN et al., 1995).

O presente trabalho teve como objetivos, determinar a prevalência sorológica da toxoplasmose entre gatos e cães do meio rural do município de Jaguapitã, Estado do Paraná, e correlacionar os títulos de anticorpos anti-T.gondii entre os felinos, caninos e o homem.

\section{MATERIAL E MÉTODOS}

Fizeram parte do estudo 40 propriedades rurais, do município de Jaguapitã, sorteadas ao acaso de um total de 506 imóveis rurais (INCRA, 1995). O município de Jaguapitã, localiza-se ao norte do Estado do Paraná, sendo formado por 10613 habitantes, com 3142 localizados na zona rural (IBGE, 1991); apresenta uma altitude de $650 \mathrm{~m}$, latitude $23^{\circ}$ sul e longitude $51^{\circ} \mathrm{W}-\mathrm{GR}$, um clima subtropical úmido mesotérmico, com média de temperatura acima de $22^{\circ} \mathrm{C}$ no verão e abaixo de $18^{\circ} \mathrm{C}$ no inverno, extensão territorial de $463,138 \mathrm{~km}^{2}$, com uma economia voltada à produção agropecuária (IPARDES, 1991).

A população estudada foram todos os cães e gatos de todas as faixas etárias, aparentemente normais, encontrados nas propriedades rurais, dos quais conseguiu-se fazer a colheita, perfazendo um total de 189 cães (116 machos e 73 fêmeas) oriundos das 40 propriedades amostradas e 163 amostras de felinos (75 machos e 88 fêmeas) oriundos de 31 propriedades. Destes foram determinados a prevalência da toxoplasmose e a correlação dos títulos de anticorpos entre as duas espécies. Com o intuito de correlacionar os títulos de anticorpos anti-T.gondii, das espécies felina e canina com a espécie humana, fizeram parte da amostragem 345 pessoas (190 homens e 155 mulheres, com idades que variaram de 5 a 78 anos) moradoras das 40 propriedades sorteadas. A amostragem populacional foi obtida utilizando-se o programa Epi-Info versão 6, com base na estimativa da população de cães e gatos (628 cães, 1 cão para cada 5 habitantes da zona rural e 314 gatos, um gato para cada 10 habitantes da zona rural) e a partir de prevalências pré-determinadas, obtendo-se amostragens epidemiologicamente significativas.

Amostras de 2 a $5 \mathrm{ml}$ de sangue foram colhidas por punção venosa, em tubos de ensaio estéreis. No laboratório, estas amostras eram incubadas em Banho Maria a $37^{\circ} \mathrm{C}$ por duas horas até retração do coágulo, em seguida centrifugados a $3000 \mathrm{rpm}$ durante 15 minutos. Posteriormente, os soros eram retirados e transferidos para frascos estéreis, identificados e armazenados a $-20^{\circ} \mathrm{C}$, até a realização dos exames. Todas as amostras colhidas eram acompanhadas de uma ficha epidemiológica, que contemplava os aspectos epidemiológicos relativos ao agente e à população em estudo.

Os soros foram submetidos à reação de imunofluorescência indireta (RIFI) para detecção de anticorpos anti-Toxoplasma gondii da classe IgG, conforme técnica descrita por CAMARGO (1964), utilizando-se soro anti - IgG para cada espécie em estudo, produzido a partir de inoculações em coelhos, conjugado ao isotiocianato de fluoresceína da marca Sigma-Chemical. Em todas as reações foram incluídos soros padrões positivo e negativo, previamente conhecidos. A leitura foi realizada em microscópio de imunofluorescência da marca NIKON. A positividade foi considerada como maior ou igual a $1: 16$.

A análise de associação entre os grupos foi testada pela análise de $X^{2}$ com significância estatística determinada se $p$ menor ou igual 0,05 . Foi calculado o coeficiente de correlação para determinar a relação da distribuição dos títulos interespécies.

\section{RESULTADOS}

Examinaram-se 163 soros felinos, dos quais $119(73 \%)$ reagentes e $44(27 \%)$ não reagentes. Os títulos mais freqüentes foram de 1:4096 $(28,6 \%)$ e $1: 256(21,8 \%)$ e o maior título encontrado foi 1:65536 $(0,8 \%)$ conforme Tabela 1 . A soropositividade aumentou com a idade $\left(X^{2}=15,26 \mathrm{com}\right.$ $p<0,0005)$ o que pode ser visualizado na Tabela 2 , porém, não apresentaram diferenças estatísticas significativas com relação ao sexo $\left(X^{2}=0,63 \mathrm{com}\right.$ $p=0,42$ ), conforme Tabela 3 .

Examinaram-se 189 soros caninos, dos quais $159(84,1 \%)$ foram reagentes e $30(15,9 \%)$ não reagentes. Os títulos mais freqüentes foram 1:64 $(38,4 \%)$ e $1: 16(31,4 \%)$, o maior título encontrado foi de 1:4096 (1,9\%) conforme Tabela 1. Considerando-se as faixas etárias, verificou-se que aqueles animais com menos de 8 meses apresentaram uma prevalência menor que as outras idades $(63,16 \%)$ 
Tabela 1 - Recíprocas dos títulos de anticorpos anti-T. gondii, através da reação de imunofluorescência indireta - IgG, em soros de humanos, felinos e caninos do município de Jaguapitã (zona rural), Paraná, Brasil, 1997.

\begin{tabular}{|c|c|c|c|c|c|c|c|c|c|c|}
\hline \multirow[b]{2}{*}{ Espécie } & \multicolumn{9}{|c|}{ Títulos de Anticorpos à RIFI } & \multirow[b]{2}{*}{ Total } \\
\hline & 16 & 64 & 256 & 1024 & 4096 & 8192 & 16384 & 32768 & 65536 & \\
\hline Humana & $\begin{array}{c}38 \\
16,7 \%\end{array}$ & $\begin{array}{c}36 \\
15,9 \%\end{array}$ & $\begin{array}{c}65 \\
28,6 \%\end{array}$ & $\begin{array}{c}44 \\
19,4 \%\end{array}$ & $\begin{array}{c}30 \\
13,2 \%\end{array}$ & $\begin{array}{c}5 \\
2,2 \%\end{array}$ & $\begin{array}{c}4 \\
1,8 \%\end{array}$ & $\begin{array}{c}3 \\
1,3 \%\end{array}$ & $\begin{array}{c}2 \\
0,9 \%\end{array}$ & 227 \\
\hline Canina & $\begin{array}{c}50 \\
31,4 \%\end{array}$ & $\begin{array}{c}61 \\
38,4 \%\end{array}$ & $\begin{array}{c}35 \\
22 \%\end{array}$ & $\begin{array}{c}10 \\
6,3 \%\end{array}$ & $\begin{array}{c}3 \\
1,9 \%\end{array}$ & 0 & 0 & 0 & 0 & 159 \\
\hline
\end{tabular}

Tabela 2 - Detecção de anticorpos anti-T.gondii, através da reação de imunofluorescência indireta - IgG, em soros de felinos e caninos, correlacionados às faixas etárias, no município de Jaguapitã (zona rural), Paraná, Brasil, 1997.

\begin{tabular}{|c|c|c|c|}
\hline \multirow[b]{2}{*}{ Faixas Etárias } & \multicolumn{2}{|c|}{ RIFI } & \multirow[b]{2}{*}{ Total } \\
\hline & Reagentes & Não Reagentes & \\
\hline \multicolumn{4}{|l|}{ Felinos } \\
\hline 1 a 12 meses & $58(61,7 \%)$ & $36(38,3 \%)$ & $94(57,7 \%)$ \\
\hline 13 a 24 meses & $31(83,8 \%)$ & $06(16,2 \%)$ & $37(22.7 \%)$ \\
\hline$>24$ meses & $30(93,8 \%)$ & $02(6,2 \%)$ & $32(19,6 \%)$ \\
\hline Total & $119(73 \%)$ & $44(27 \%)$ & 163 \\
\hline \multicolumn{4}{|c|}{$\left(X^{2}=15,26 p<0,0005\right)$} \\
\hline \multicolumn{4}{|l|}{ Caninos } \\
\hline 3 a 8 meses & $12(63,16 \%)$ & $7(36,84 \%)$ & $19(10,05 \%)$ \\
\hline 9 a 12 meses & $31(88,57 \%)$ & $4(11,43 \%)$ & $35(18,51 \%)$ \\
\hline 13 a 24 meses & $37(78,73 \%)$ & $10(21,27 \%)$ & $47(24,87 \%)$ \\
\hline 25 a 48 meses & $50(94,34 \%)$ & $3(5,66 \%)$ & $53(28,04 \%)$ \\
\hline$>48$ & $29(82,86 \%)$ & $6(17,14 \%)$ & $35(18,52 \%)$ \\
\hline Total & $159(84,1 \%)$ & $30(15,9 \%)$ & 189 \\
\hline \multicolumn{4}{|c|}{$\left(X^{2}=11,98 p=0,017\right)$} \\
\hline
\end{tabular}

com $X^{2}=11,98$ com $p=0,017$ que pode ser visualizado na Tabela 2 . Com relação ao sexo não houve diferenças estatísticas significativas na distribuição dos sororeagentes ( $X^{2}=0,42$ com $\left.p=0,51\right)$, conforme Tabela 3.

Dos 345 humanos testados, 190 eram do sexo masculino e 155 do sexo feminino, com idades que variaram de 5 a 78 anos, obteve-se uma prevalência para a toxoplasmose através da RIFI de $65,8 \%$. O maior título encontrado foi de 1:65536 $(0,9 \%)$ e os mais freqüentes de 1:256 $(28,6 \%)$ e 1:1024 (19,4\%), conforme observa-se na Tabela 1 .

Não se observou correlação positiva e significativa na comparação dos títulos de anticorpos anti-T.gondii entre as espécies felina e canina
Tabela 3 - Detecção de anticorpos anti-T.gondii, através da reação de imunofluorescência indireta - IgG, em soros de felinos e caninos, correlacionados ao fator sexo, no município de Jaguapitã (zona rural), Paraná, Brasil, 1997.

\begin{tabular}{cccc} 
& \multicolumn{3}{c}{ RIFI-IgG } \\
\cline { 2 - 4 } Sexo & Reagente & Não Reagente & Total \\
& \multicolumn{3}{c}{ Felinos } \\
Macho & $57(76 \%)$ & $18(24 \%)$ & $75(46 \%)$ \\
Fêmea & $62(70,5 \%)$ & $26(29,5 \%)$ & $88(54 \%)$ \\
Total & $119(73 \%)$ & $44(27 \%)$ & 163 \\
& $\left(X^{2}=0,63\right.$ & $p=0,42)$ & \\
Macho & $96(82,8 \%)$ & $20(17,2 \%)$ & $116(61,4 \%)$ \\
Fêmea & $63(86,3 \%)$ & $10(13,7 \%)$ & $73 \quad(38,6 \%)$ \\
Total & $159(84,1 \%)$ & $30(15,9 \%)$ & 189 \\
& $\left(X^{2}=0,42\right.$ & $p=0,51)$ & \\
& &
\end{tabular}

( $p=0,39)$. Obteve-se uma correlação positiva e significativa na comparação dos títulos de anticorpos anti-T.gondii entre as espécies humana e felina $(\mathrm{r}=0,78 \mathrm{p}=0,01)$ e humana e canina $(\mathrm{r}=0,64 \mathrm{p}=0,05)$. A comparação dos títulos de anticorpos antiT.gondii interespécie pode ser verificado na Tabela 1 e na Figura 1.

\section{DISCUSSÃO}

A elevada prevalência em cães e gatos observada no estudo, pode ser consistente quando 


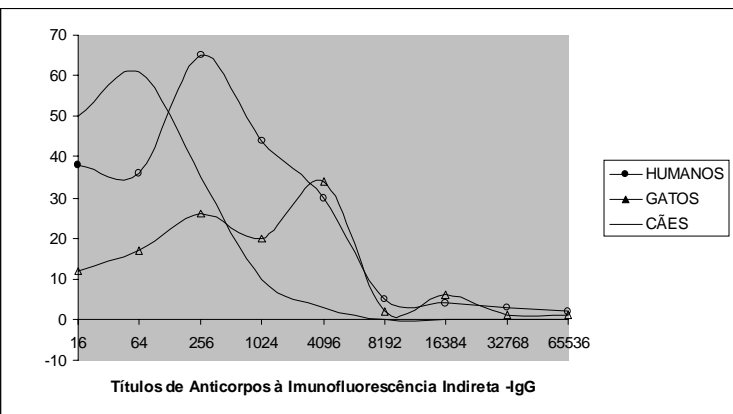

Figura 1 - Curva da recíproca dos títulos de anticorpos antiToxoplasma gondii, através da reação de imunofluorescência indireta - IgG, demostrando a correlação entre as espécies Humana , felina e Canina, oriundas de propriedades rurais, Jaguapitã, Paraná, Brasil, 1997

comparada com a frequiência de soropositividade encontrada para a toxoplasmose, em diferentes regiões, valendo-se de diferentes testes sorológicos, conforme a espécie estudada, onde encontraram variações de 19,6 a 52,7\% nos cães (JACKSON $\boldsymbol{e t}$ al., 1987; BANETH $\boldsymbol{e t}$ al., 1996; DURAN et al., 1995 ) e 19 a 68,3\% em gatos (LARSON et al., 1987; JACKSON et al., 1987; DUBEY et al., 1995b).

Considerando-se a soroprevalência para a espécie felina, demonstrou-se uma alta soropositividade $(73 \%)$, o que pode caracterizar uma elevada taxa de infecção pelo parasita e, provavelmente, um alto grau de oocistos eliminados no meio ambiente anteriormente (DUBEY $\boldsymbol{e t} \boldsymbol{a l} ., 1995 b)$, uma vez que, em infecções por bradizoítos nos felinos, anticorpos IgG são detectados após o término da eliminação de oocistos nas fezes (DUBEY et al., 1995a).

O número de gatos soropositivos é provavelmente um melhor indicativo do risco de exposição ao $T$. gondii que a soroprevalência, pois a carga de oocistos no meio ambiente está mais associada à quantidade do que à proporção de gatos infectados (WEIGEL et al., 1995). Felinos podem eliminar milhões de oocistos em um único dia e estes podem sobreviver no meio ambiente por mais de 1 ano (DUBEY \& BEATTIE, 1988).

Títulos mais freqüentes, nos felinos, foram 1:4096 $(28,6 \%)$ e 1:256 $(21,8 \%)$, discordando de outros autores, como MENDEZ (1983), que encontrou maior frequiência nos títulos de 1:64 através da RIFI, bem como LARSSON et al.(1987) e WILKINSON \& THOMPSON (1986), o primeiro observou $70 \%$ de título entre 1:64 e 1:256 pela reação de Sabin - Feldman, e o segundo, pela Hemaglutinação Indireta, observou a maioria dos títulos entre 1: 64 (25\%)

A distribuição dos títulos de anticorpos nos felinos pesquisados, mostra que grande parte dos animais soropositivos apresentavam-se com títulos maior ou igual a 1:4096 (36,9\%), o que pode ser característico de uma infecção recente, quando comparada aos títulos obtidos pela sorologia humana (CAMARGO, 1975), embora, títulos elevados nos felinos possam permanecer por até mais de 29 meses (DUBEY \& THULLIEZ, 1989). Analisando as faixas etárias dos felinos, conforme esperado, verificou-se um aumento da soropositividade com as idades $(p<0,0005)$, resultados que se assemelham a outros estudos (MENDEZ, 1983; DUBEY et al., 1995b; LARSSON et al., 1987); no entanto, JACKSON et al. (1987) não observaram diferenças estatísticas significativas, nas diferentes faixas etárias. Pode-se observar com o estudo, que grande parte dos felinos infectam-se precocemente ainda enquanto jovens $(61,7 \%)$, resultados também observados por DUBEY et al. (1995b), também pesquisando animais de propriedades rurais. WEIGEL et al. (1995), relataram um maior risco da infecção toxoplásmica em criações de suínos, quando as propriedades apresentavam um maior número de gatos jovens soropositivos ao $\boldsymbol{T}$. gondii. Com relação ao sexo dos felinos, esta variável não alterou a distribuição dos sororeagentes, resultados semelhantes foram observados por outros pesquisadores (MENDEZ, 1983; LARSSON et al.,1987; JACKSON et al., 1987).

Com relação às faixas etárias, observou-se uma soropositividade menor em cães com menos de 8 meses $(63,16 \%)$, apesar de demonstrar que grande parte dos animais se infectam ainda jovens. Reforçaram esses resultados aqueles obtidos por JACKSON et al. (1987), onde a soroprevalência foi menor nos animais com menos de 6 meses. A maioria dos títulos de anticorpos nos caninos apresentaram-se entre $1: 64(38,4 \%)$ e $1: 16(31,4 \%)$, caracterizando grande parte dos animais $(69,8 \%)$, em uma fase que pode ser classificada como latente ou inicial da doença (CAMARGO, 1975), resultados esses que se assemelham aos obtidos por ULÓN \& MARDER (1990); BANETH et al.(1996); LAZZAROTTO et al.(1996) e LAGAGGIO $\boldsymbol{e t}$ al.(1997). Não se observou no estudo diferenças significativas na distribuição dos sororeagentes em relação ao sexo dos caninos, o que também é relatado por outros pesquisadores (BANETH, 1996; DURAN et al.,1995; NAVARRO et al.,1997).

Com relação aos resultados obtidos no estudo da população humana, estes foram semelhantes aos observados por GARCIA \& NAVARRO (1995), os quais, estudando a população da zona rural da macro região de Londrina, observaram $71,3 \%$ de sororeagentes a toxoplasmose, verificaram, ainda, títulos mais frequientes de 1:1024 e 
1:4096 (ambos com 29,2\%) e 1:256 (26,8\%), e maior título de 1:65536, corroborando com os resultados do estudo atual. Com base na correlação dos títulos de anticorpos entre os felinos e caninos, não se obteve significância nos resultados encontrados, o que pode demostrar que os felinos e os cães, pelos seus hábitos alimentares distintos, estejam se expondo a diferentes vias de transmissão, os gatos pelo seu hábito alimentar exclusivamente carnívoro e caçador e os cães através de sobras de alimento humano.

Demostrou-se, porém, uma correlação positiva e significativa entre os títulos de anticorpos dos humanos com os dos felinos, e dos humanos com os caninos, o que pode estar relacionado ao fato do homem estar compartilhando as mesmas vias de transmissão em relação aos cães, ou seja, a alimentação; e em relação à correlação humana e felina, a presença dos gatos é provavelmente a causa dessa correlação positiva.

ULÓN \& MARDER (1990), comparando os títulos de anticorpos entre humanos, cães e gatos de convívio urbano, demostraram uma correlação positiva e altamente significativa somente entre as pessoas e os cães analisados $(\mathrm{r}=0,69 p<0,005)$, semelhante ao observado no presente estudo, quando comparado à correlação dos títulos de anticorpos anti-T. gondii entre o homem e o cão $(\mathrm{r}=0,64$ $p=0,05)$.

\section{CONCLUSÃO}

A toxoplasmose está largamente distribuída nas espécies felina e canina da zona rural do município, bem como foram demonstradas correlações positivas e significativas entre os títulos de anticorpos anti-T.gondii, na comparação entre as espécies humana-felina e humana-canina.

\section{REFERÊNCIAS BIBLIOGRÁFICAS}

BANETH, G., SHKAP, V., SAVITSKY, I. et al. The prevalence of antibodies to Toxoplasma gondii in dogs in Israel. Israel J Vet Med, v. 51, n. 1, p. 31-33, 1996.

CAMARGO, M.E. Improved tchnique of indirect imunofluorescence for serological diagnosis of toxoplasmosis. Rev Inst Med Trop de São Paulo, v. 6, n. 3, p. 117-118, 1964.

CAMARGO, M.E. Diagnóstico sorológico da toxoplasmose na gravidez . Rev Ass Med Bras, v. 21, n. 11, p. 341-346, 1975.

DUBEY, J.P. Toxoplasma, Neospora, Sarcocystis and other tissue cyst- forming of human and aniamls. In: KRIER, JP Parasitic Protozoa, 2.ed. San Diego: Academic Press, 1993, p. 1-157.

DUBEY, J.P., BEATTIE, C.P. Toxoplasmosis of animals and man. Boca Ratton: CRC Press, 1988.
DUBEY, J.P., LAPPIN, M.R.; THULLIEZ, P. Long term antibody responses of cat fed Toxoplasma gondii tissue cysts. J Parasitology, v. 81, n. 6, p.8 87-893, 1995a.

DUBEY, J.P., THULLIEZ ,P. Serologic diagnosis of toxoplasmosis in cats fed Toxoplasma gondii tissue cysts. J Am Vet Med Ass, v. 194, n. 9, p. 1297-1299, May. 1989.

DUBEY, J.P., WEIGEL, R.M., SIEGEL, A.M. et al. Sources and reservoirs of Toxoplasma gondii infection on 47 swine farms in Illinois. J Parasitol, v. 81, n. 5, p. 723-729, 1995 b.

DURAN, F.P., CABRAL, D.D., FERREIRA, F. et al. Freqüência de anticorpos anti-Toxoplasma gondii (NICOLLE E MANCEAUX , 1909) em cães clinicamente sadios da cidade de Uberlândia - MG. In : IX SEMINÁRIO BRASILEIRO DE PARASITOLOGIA VETERINÁRIA, 1995. Campo Grande, MS. Anais ... Campo Grande, 1995, p. 228.

FUNDAÇÃO INSTITUTO BRASILEIRO DE GEOGRAFIA E ESTATÍSTICA (IBGE). Sinapse preliminar do Censo demográfico: resultados do universo relativos às características da população e dos domicílios, Paraná. Rio de Janeiro: IBGE, 1991. N. 20.

GARCIA, J.L., NAVARRO, I.T. Levantamento soroepidemiológico da toxoplasmose em moradores da zona rural do município de Guaraci - Paraná - Brasil. Semina: Ciências Agrárias, v. 16, n. 1,p. 63-67, 1995.

INSTITUTO NACIONAL DE COLONIZAÇÃO E REFORMA AGRÁRIA (INCRA). Relação de Certificados de Cadastro e Notificações de Imóveis Rurais Emitidos, 714151Jaguapitã, Paraná. INCRA, 1995.

INSTITUTO PARANAENSE DE DESENVOLVIMENTO ECONÔMICO E SOCIAL (IPARDES). Caderno de Estatísticas Municipal. Jaguapitã: IPARDES, 1991.

JACKSON, M.H., HUTCHISON, W.M., SIIM, J.C. Prevalence of Toxoplasma gondii in meat animals, cats and dogs in central Scotland. Br Vet J, v. 143, n. 2, p. 159-165, 1987.

LAGAGGIO, V.R.A., FlORES, M.L., ALVES, C.S.P. et al. Hemaglutinação passiva para toxoplasmose em cães da região central do RS. Rev Bras Parast Vet, v. 6, n. 2 supl.1, p. 342, Ago. 1997.

LARSSON, C.E., JAMRA, L.M. F., RIBEIRO, M.F. Prevalência de toxoplasmose felina determinada pela reação de Sabin Feldman, em São Paulo . In: I CONGRESSO BRASILEIRO DE ZOONOSES, 1987. Anais... Rio de Janeiro: 1987, p. 7071 .

LAZZAROTTO, J.J., PITT, G.L., LAGAGGIO, V.R. $\boldsymbol{e}$ t al. Hemaglutinação passiva para toxoplasmose em cães de região central do RS. In : XV CONGRESSO PANAMERICANO DE CIÊNCIAS VETERINÁRIAS, 1996. Campo Grande, MS. Anais... Campo Grande: 1996, p. 263.

MILLER, N.L., FRENKEL, J.K., DUBEY, J.P. Oral infections with Toxoplasma cysts and oocysts in felines, other mammals and birds. J Parasitology, v. 58, p. 928-937, 1972 .

MENDEZ, L.D.V. Prevalência de coccídios e anticorpos antitoxoplásmicos em gatos domésticos de Porto Alegre, RS - Brasil. Porto Alegre-RS. 38p. Dissertação (Mestrado em Medicina Veterinária) - Escola de Medicina Veterinária .Universidade Federal do Rio Grande do Sul, 1983. 
NAVARRO, I.T., FREIRE, R.L., OGAWA, L. et al. Antibodies against Toxoplasma gondii in plasma of dogs seen at the UEL Veterinary Hospital. Epiodémiol Santé Animale, v. 2, n. 3132 , p. 47,1997

ULÓN, S.N., MARDER, G. Tasas de infección toxoplasmica en el hombre y su relacion con los animales domesticos en la ciudad de Corrientes. Vet Arg, v. 7, n. 68, p. 518-522, Oct. 1990
WEIGEL, R.M., DUBEY, J.P., SIEGEL, A.M. et al. Risk factors for transmission of Toxoplasma gondii on swine farms in Illinois. J Parasitol, v. 81, n. 5, p. 736-741, 1995.

WILKINSON, G.T., THOMPSON, H.L. Prevalence of Toxoplasma gondii antibodies in cats in south-east Queensland. Aust Vet Practit, v. 16, n. 3, p. 144-146, Sep. 1986.

Ciência Rural, v. 29, n. 1, 1999. 